\title{
A SIMPLISTIC APPROACH TO STRUCTURAL DYSPLASIA ASSESSMENT: DESCRIPTION AND VALIDATION
}

\author{
T. BATTINELLI, EDD \\ Physical Education Department, Fitchburg State College, \\ Fitchburg, Massachusetts 01420
}

\begin{abstract}
The purpose of this study was to formulate a simplistic method of assessing human structural dysplasia and to validate a classification system that would objectively categorise the type and extent of such dysplasia through the use of indices. Anthropometric measurements were taken from a sample of $\mathbf{2 2 2}$ male college students, length/breadth ratios were formulated, and upper/lower body classifications were made in terms of type and subtype dysplasia. Correlation validation results were highly significant. Body composition data information was also provided for descriptive purposes.
\end{abstract}

\section{INTRODUCTION}

Measorement of human structural dysplasia is not new to the field of anthropometric morphology. Over the years, dysplasia typologies have been developed and have exemplified the growth of such systems. Earlier classification methodologies were centred around the measurement of the extremes of body types (Kretschmer, 1925), the structural disharmony of body parts (Viola, 1937), and the integration of unequal component (endomorphy, mesomorphy, and ectomorphy) mixtures in the different regions of the body (Sheldon et al, 1940). Subjective (anthroposcopic) and objective (anthropometric) methods of study were utilised in the makeup of these systems.

Recent typological systems of dysplasia, however, have demonstrated a more uniform approach to such assessment. Dysplasia can be described as the structural deviation from a given norm and the measurement methodology has been more index oriented. Unlike the earlier body type and somatotype oriented systems of classification, indices are generally computed from ratios of two or more measures that directly demonstrate the anthropometric differences of body parts to one another relative to representative average norms. The measures involved usually include those of height, weight, body lengths, breadths, and circumferences.

Hirata $(1964,1966)$ employing his Stout-Lean FIndex, studied the physiques of Japanese athletes at the Tokyo Olympics. He described and classified the diversity of body builds among the athletes from a variety of sports activities. Behnke (1968) demonstrated structural bodily deviations through somatogram representations of body size and shape which noted disharmonies from designated norms relative to skeletal and girth measurements. Dupertuis (1974) developed a structural profile describing dysplasia through percentage breadth/height ratio deviations from average values. Battinelli (1974-1977) used the Dupertuis' formulas in his development of a positive/ negative upper/lower body dysplasia classification system.

The purpose of this study is to formulate a simplistic method of assessing human structural dysplasia and to validate a classification system that will objectively categorise the type (direction) and subtype (extent) of such dysplasia through the use of indices.

\section{Dysplasia Assessment and Classification}

The anthropometric data used in this study was obtained from 222 male college students from Fitchburg State College in Fitchburg, Massachusetts. The structural measurements were taken according to the measurement descriptions and on the designated landmarks advanced by Behnke and Royce (1966). The anthropometric landmarks included those of the upper (biacromial, chest, elbow, and wrist breadths) and lower (biiliac bitrochanteric, knee, and ankle breadths), trunks and limbs. Height measurements 
were also obtained. All of the anthropometric measurements were repeated until they were with in 1 percent reliability limits. The ratios used to determine type and subtype structural differences were formulated by the investigator. Height/breadth indices were computed for each of the subjects, wherein height was divided by the upper and lower body breadth measurements through the use of two separate formulas.

Upper body dysplasia index $=$

$$
\frac{\text { Height }}{\text { Biacromial + chest + elbows + wrists }}
$$

Lower body dysplasia index $=$

$$
\frac{\text { Height }}{\text { Biiliac + bitrochanteric }+ \text { knees }+ \text { ankles }}
$$

Type and subtype dysplasia classifications were then made in terms of the group mean and standard deviation scores for each of the subjects (Table I and Dysplasia Type Representations).

\section{TABLE I}

Classification of dysplasia into types (letters) and subtypes (symbols) on the basis of direction and extent of upper trunk and arms and lower trunk and legs relative to mean and standard deviation units.

$$
\begin{aligned}
& \begin{array}{l}
\text { Upper Trunk } \\
\text { and Arms }
\end{array} \\
& -2 \text { S.D. Units } \\
& \text { B-/B-- B-/B- B-/L+ } \quad B-/ L++ \\
& \text { Mean } \\
& \mathrm{L}^{+/ B}--\quad \mathrm{L}+/ \mathrm{B}-\quad \mathrm{L}+/ \mathrm{L}+\quad \mathrm{L}+/ \mathrm{L}++
\end{aligned}
$$

+2 S.D. Units

$$
\begin{aligned}
& L_{++/ B}-\quad L++/ B-\quad L++/ L+L++/ L++ \\
& -2 \text { S.D. Units Mean }+2 \text { S.D. Units }
\end{aligned}
$$$$
\text { Lower Trunk and Legs }
$$

Key:

Upper Trunk and Arms/Lower Trunk and Legs

$B=$ Breadth predominance relative to length (direction)

$L=$ Length predominance relative to breadth (direction)

+ or $-=$ Slight predominance (extent)

++ or $--=$ Marked predominance (extent)

S.D. = Standard Deviation

\section{Body Composition and Assessment}

The anthropometric measurements that were taken were also utilised to assess the body composition
DYSPLASIA TYPE REPRESENTATIONS

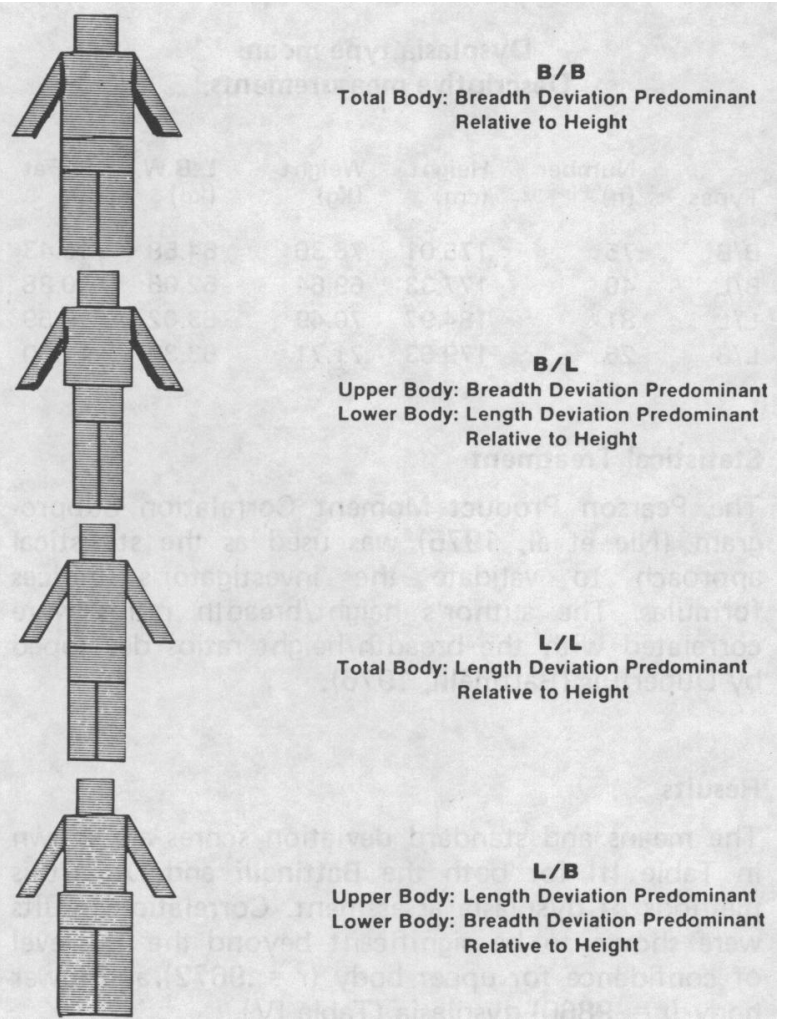

levels of lean body weight and percentage of body fat according to the formulas developed by Behnke and Royce (1966).

$$
\begin{gathered}
\text { L.B.W. }=D \times h^{2} \\
\% \text { Fat }=\frac{\text { Body weight-L.B.W. }}{\text { Body weight }} \times 100
\end{gathered}
$$

\section{Descriptive Data Results}

The descriptive mean data for the dysplasia groups are shown in Table II. The greatest number of subjects (75) were classified as B/B dysplasia types, while the fewest (26) were found to be in group L/B. Type dysplasia was concentrated with in the $B / B$ and $L / L$ groups rather than the $B / L$ and $L / B$ structural deviation combinations. Subtype dysplasia was concentrated around the mean and was not evenly dispersed. As was expected, the B/B dysplasia types were the shortest in height, heaviest in weight, and possessed the greatest amounts of lean body weight and percentage of body fat. The $L / L$ types were the tallest in height and possessed the lowest percentage of body fat. 
TABLE ॥

Dysplasia type mean.

Descriptive measurements.

$\begin{array}{llllll}\text { Types } & \begin{array}{l}\text { Number } \\ (\mathrm{n})\end{array} & \begin{array}{l}\text { Height } \\ (\mathrm{cm})\end{array} & \begin{array}{l}\text { Weight } \\ (\mathrm{kg})\end{array} & \begin{array}{l}\text { L.B.W. } \\ (\mathrm{kg})\end{array} & \begin{array}{l}\% \text { Fat } \\ \%\end{array} \\ \text { B/B } & 75 & 175.01 & 76.36 & 64.58 & 15.43 \\ \text { B/L } & 40 & 177.33 & 69.64 & 62.06 & 10.88 \\ \text { L/L } & 81 & 184.97 & 70.49 & 63.02 & 10.59 \\ \text { L/B } & 26 & 179.63 & 71.71 & 63.39 & 11.60\end{array}$

\section{Statistical Treatment}

The Pearson Product Moment Correlation Subprogram (Nie et al, 1975) was used as the statistical approach to validate the investigator's indices formulas. The author's height/breadth ratios were correlated with the breadth/height ratios developed by Dupertuis (Battinelli, 1976).

\section{Results}

The means and standard deviation scores are shown in Table III for both the Battinelli and Dupertuis methods of dysplasia assessment. Correlation results were shown to be significant beyond the .01 level of confidence for upper body $(r=.9672)$ and lower body $(r=.9860)$ dysplasia (Table IV).

\section{TABLE III}

Upper/Lower Body Dysplasia. Mean and Standard Deviation Scores.

$\begin{array}{lllc}\text { Variable } & \text { Cases } & \text { Mean } & \begin{array}{l}\text { Standard } \\ \text { Deviation }\end{array} \\ \begin{array}{llll}\text { Upper body } \\ \text { Dysplasia }\end{array} & 222 & 1.88448 \text { (B) } & .093269 \text { (B) } \\ \text { Lower Body } & & 100.587 \text { (D) } & 4.68600 \text { (D) } \\ \text { Dysplasia } & 222 & 1.88767 \text { (B) } & .087395 \text { (B) } \\ & & 099.851 \text { (D) } & 4.69127 \text { (D) }\end{array}$

(B) - Battinelli Indices

(D) - Dupertuis Indices
TABLE IV

\section{Upper/Lower Body Dysplasia.} Correlations.

$\begin{array}{lll} & \begin{array}{l}\text { Upper Body } \\ \text { Dysplasia (D) }\end{array} & \begin{array}{l}\text { Lower Body } \\ \text { Dysplasia (D) }\end{array} \\ \begin{array}{l}\text { Upper Body } \\ \text { Dysplasia (B) }\end{array} & -.9672 & -.7082 \\ \text { Lower Body } & & \\ \text { Dysplasia (B) } & -.7169 & -.9860\end{array}$

\section{Discussion}

Criticisms have been directed towards the use of body build indices in the study of human constitutional morphology. Sills (1974) in an overview of the field of anthropometry reported that the use of two or three measurements did not satisfactorily provide pertinent body build rating data. Domey, Duckworth and Morandi (1964) in their analysis of physique rating systems stated that body build indices provided only basic data and insufficient information necessary for effective constitutional analysis.

In his approach, the author has tried to provide such basic representative data along with the more changeable body composition aspects necessary for constitutional assessment. All of the breadth measurement landmarks relative to height were used in the ratio formulations instead of the one or two factorial representatives common to indices utilisation. Descriptive data information such as height, weight, lean body weight, and percent of body fat were also provided.

In reference to the processes of assessment, calculative statistical utilisation of the mean and standard deviation units enabled the investigator to provide method objectivity and to express upper/lower body length/breadth ratio deviations from the norm.

The results of this study show that the investigator's simplistic method of dysplasia assessment and classification with additional reference information gained from body composition measurement can objectively identify and qualify disharmonic morphological types and subtypes.

\section{REFERENCES}

Battinelli, Thomas, 1976 "Constitutional disharmony and selected components of motor ability". Human Biol. 48 (3): 465-474.

Battinelli, Thomas, 1977 "The dysplasia build of college athletes". Ath.Admin. 11 (4). 
Behnke, A. R., 1968 "Physique and exercise". Exercise Physiology (New York: Academic Press), $359-385$.

Behnke, A. R. and Royce, J., 1966 "Body size, shape, and composition of several types of athletes". J.Sports Med. and Phys. Fitness 6: 75-88.

Domey, R. G., Duckworth, J. E. and Morandi, A. J., 1964 "Taxonomies and correlates of physique". Psych.Bull. 62: $411-426$.

Dupertuis, C. W., 1974 “The structural profile”. Amer.J.Phys.Anthrop. 41 (3): 476.

Hirata, K., 1964 "The evaluating method of physique and physical fitness and its practical application". Gifu Prefecture: Hirata Institute.

Hirata, K., 1966 "Physique and age of Tokyo Olympic champions". J.Sports Med.and Phys.Fitness 6: $207-222$.

Kretschmer, E., 1925. Physique and Character. Trans. Walter John Hubert Sprott. (Harcourt, Brace, New York).

LeVeau, B., Ward, T. and Nelson, R. C., 1974 "Body dimensions of Japanese and American gymnasts". Med.and Scie. in Sports 4: 146-150.

Nie, N. H., Hull, Ch. H., Jenkins, J. S., Steinbrenner, K. and Dent, D., 1975. Statistical Package for the Social Sciences. McGraw-Hill, New York.

Sheldon, W. H., Stevens, S. S. and Tucker, W. B., 1940. The Varieties of Human Physique. (Harper, New York).

Sills, F. B., 1974 "Anthropometry in relation to physical education". Science and Medicine of Exercise and Sport, Harper and Row, 2: 24-33.

Viola, G., 1937 "Il mio metodo di valutazione della costizione individuale". Endocrinologia e Patologia Costituzionale 12: $387-480$.

Title:

BOOK REVIEW

Author: $\quad$ Florence Paterson Kendall, PT and Elizabeth Kendall McCreary

Publisher: $\quad$ Williams \& Wilkins, 1983

Price: $£ 20.75$

It is thirty years since the first edition of this book was published during the period when poliomyelitis epidemics were common. This, the third edition, has been expanded to include a section of muscle function in relation to posture and includes remedial exercise programmes.

The book starts with a chapter on Fundamental Principles in Manual Muscle Testing, and goes on to describe isolated and combined joint motion. This is followed by the technique, planning and use of spinal nerve and muscle charts. A page is then given over to each individual muscle, and includes an anatomical illustration of the muscle, photographs demonstrating the techniques of testing function and an explicit, clearly laid out text to support the illustrations and discuss the effects of weakness or contracture in the muscle. The quality and printing of illustration, photograph and text is excellent. The book ends with a short bibliography and an extensive list of further selected reading.

The book is a reference volume that any Physiotherapy Department would welcome in its library. I would like to see it expanded further to include basic muscle and joint mechanics and chapters on the modern techniques of gait analysis and kinesiology. Whilst accepting the limitations the authors set, it is a pity that occasionally they do not refer to possible underlying pathologies; for example, six pages are given over to testing for hamstring tightness without a reference that this may be due to mechanical instability in the lower lumbar spine.

The physiotherapy student may find that this book will relieve buying an anatomical tome, but for the medical clinician the small M.R.C. booklet on Muscle Testing, which fits easily into a pocket, is more functional.

J. A. Robertson 